theoretical credo, their interests intersected in many areas; they seemed to have stimulated each other's thinking enough to have written two joint papers on rather disparate subjects, but in areas which occupied each of them over many years. One of these papers is on Mordvinian metrics and was first published in German in 1941 and later in a slightly expanded version in English as "Axioms of a Versification System, Exemplified by the Mordvinian Folksong," Linguistica (Stockholm), 1 (1952): 5-13. The other paper is on phonological theory: "Notes on the French Phonemic Pattern," Word, 5 (1949): 151-58. Both papers are landmarks; the latter is a precursor of generative phonology. The only more direct connection with the Slavic field that I know of is a translation of Nikolai Berdiaev's Novoe srednevekov'e: Razmyshlenie o sud'be Rossii v Evropy, on which Lotz collaborated with Géza Sebestyén while he was still a student (Budapest, 1935). See also "Jakobson's Case Theory and the Russian Prepositions," in To Honor Roman Jakobson (The Hague, 1967, pp. 1207-12). For more details on Lotz's contribution to linguistics see the obituary in the Linguistic Society of America Bulletin, no. 60, March 1974.

Lotz's lasting interest in Hungarian and Swedish linguistics took him back to Hungary and Sweden during the latter part of his life. He was visiting professor in Stockholm in 1962-63 and guest professor in Budapest in 1966 and again in 1972. The Hungarian Academy of Sciences elected him to honorary membership in 1973.

All those-students, colleagues, administrators-who came in contact with Lotz were struck by his uncanny ability to formulate problems in any field: he would do this economically, in large strokes, and sometimes with a certain amount of entertaining and humorous cynicism, but without malice. There are few others, even if they had as discerning and incisive a mind as his, who knew how to blend culture with life so successfully.

ROBERT AUsterlitz

Columbia University

\title{
RODERICK PAGE THALER, 1927-1974
}

Roderick Page Thaler was born and raised in Tennessee and graduated with a B.A. degree in history in 1947 from the University of Tennessee. Upon receipt of the M.A. degree from the University of Illinois in 1948, he attended Harvard University and was one of Professor Michael Karpovich's first students to earn the Ph.D. (1955). Following brief service as an instructor at the University of Rhode Island, Thaler accepted a call to Bishop's University in Canada, where he served until his death in mid-January 1974. Professor Thaler's principal fields of scholarly interest were Russian and Byzantine history. His superb editorship of Leo Wiener's translation of Radishchev's Journey from St. Petersburg to Moscow has set standards which his colleagues will long seek to emulate. Those of us who have had the privilege of knowing Roderick Thaler will also deeply miss the warmth and the sincere interest which he brought to his associations with colleagues and friends. 